\title{
MENGKAJI MODEL MOOD SWING IBU HAMIL DI KOTA PALU PADA TRIMESTER PERTAMA MELALUI PERSAMAAN DIFERENSIAL BIASA ORDE 2 TAK HOMOGEN
} (Studi Kasus: Puskesmas Birobuli)

\author{
Nuranisa' ${ }^{1}$ R. Ratianingsih², A. I. Jaya ${ }^{3}$ \\ 1,2,3Program Studi Matematika Jurusan Matematika FMIPA Universitas Tadulako \\ Jalan Soekarno-Hatta Km. 09 Tondo, Palu 94118, Indonesia. \\ ${ }^{1}$ Nuranisamuslimin442@yahoo.co.id, 2,3Ratianingsih@yahoo.com
}

\begin{abstract}
The phase of first trimester has a symptoms that affect pregnant women. One of them is the rapid change in mood or mood swings. Assume only Estrogen and Progesterone will influence the mood on this model. In this research will be discussed second order of inhomogeneous differential equation model that linking mood swings pregnant women in the first trimester of pregnancy. The model is derived from Newton's second law equation and the equation of mass spring system in order to obtain the dynamics of maternal mood. The model is adaptation $\frac{\mathrm{d}^{2} \mathrm{R}}{\mathrm{dt}^{2}}+\beta \cdot \frac{\mathrm{dR}}{\mathrm{dt}}+\omega^{2} \cdot \mathrm{R}(\mathrm{t})=\mathrm{F}(\mathrm{t})$. From the simulation graph model formulation mood, the data samples taken from pregnant women who consulted in PHC Birobuli at April until May 2014. By the samples that taken from the simulation the koleris characters tend to have positive mood and stable with a value of $\beta=4$ and $\omega^{2}=0,3$, the melancholy characters mood tend to be negative but remained stable with a value of $\beta=-3,5$ and $\omega^{2}=-0,4$, the character plegmatis have positive and stable mood tends to the value of $\beta=4$ and $\omega^{2}=0,3$, while the sanguine character tends to have a positive mood and stable with a value of $\beta=4,8$ and $\omega^{2}=0.26$.
\end{abstract}

Keywords : First Trimester, Mood Swing, , Second Order of Inhomogeneous Differential Equation, The Equation of Mass Spring System

\section{ABSTRAK}

Fase trimester pertama terdapat gejala yang mempengaruhi ibu hamil. Salah satunya adalah perubahan suasana hati yang cepat atau mood swing. Model ini mengasumsikan bahwa yang mempengaruhi mood adalah hormon Estrogen dan hormon Progesteron. Dalam penelitian ini akan dibahas model persamaan diferensial orde 2 tak homogen yang mengaitkan mood swing ibu hamil pada kehamilan trimester pertama. Model ini diturunkan dari persamaan hukum Newton II dan persamaan sistem pegas massa sehingga diperoleh dinamika mood ibu hamil. Adaptasi model yang didapatkan adalah $\frac{\mathrm{d}^{2} \mathrm{R}}{\mathrm{dt}^{2}}+\beta \cdot \frac{\mathrm{dR}}{\mathrm{dt}}+\omega^{2} \cdot \mathrm{R}(\mathrm{t})=\mathrm{F}(\mathrm{t})$. Dari formulasi model dilakukan simulasi grafik mood, data sampel diambil dari para ibu hamil yang berkonsultasi di Puskesmas Birobuli pada bulan April sampai Mei 
tahun 2014. Dari simulasi sampel yang diambil didapatkan pada karakter koleris memiliki mood cenderung positif dan stabil dengan nilai $\beta=4$ dan $\omega^{2}=0,3$, karakter melankolis memiliki moodcenderung negatif namun tetap stabil dengan nilai $\beta=-3,5$ dan $\omega^{2}=-0,4$, karakter plegmatis memiliki mood cenderung positif dan stabil dengan nilai $\beta=4$ dan $\omega^{2}=0,3$ sedangkan karakter sanguinis memiliki mood cenderung positif dan stabil dengan nilai $\beta=4,8$ dan $\omega^{2}=$ 0,26 .

Kata Kunci : Mood Swing, Persamaan Diferensial Orde 2 Tak Homogen, Persamaan Sistem Pegas Massa, Trimester Pertama

\section{LATAR BELAKANG}

Kehamilan membawa perubahan baik secara fisik maupun psikologis. Kehamilan bisa menimbulkan perasaan senang, gelisah, riang, dan kelelahan, bahkan kadang - kadang semuanya bisa muncul secara bersamaan. Perubahan hormon pada tubuh ibu hamil akibat kehamilan adalah salah satu penyebabnya. Perubahan ini mengakibatkan naik turunnya moodibu hamil terutama pada fase trimester pertama. Gejala yang terjadi saat kehamilan inilah yang seringkali dianggap sebagai penyebab perubahan suasana hati yang cepat atau bisa dikatakan mood swing pada ibu hamil. Menurut Americanpregnancy, mood swing biasanya terjadi pada ibu hamil di periode 6 hingga 10 minggu, menghilang di trimester kedua dan kembali datang lagi pada trimester ketiga saat tubuh ibu hamil bersiap untuk melahirkan [3].

Banyak hormon naik secara signifikan yang mempengaruhi naik turunnya mood ibu hamil, dua diantaranya adalah hormon Estrogen dan hormon Progesteron. Perubahan suasana hati para ibu hamil bisa dipengaruhi banyak hal, tidak dapat dikatakan bahwa gejala yang terjadi saat kehamilan merupakan satu-satunya faktor yang mempengaruhi terjadinya mood swing. Kepribadian, karakter dan juga kondisi kehidupan ibu hamil pun cukup mempengaruhi terjadinya perubahan suasana hati. Persamaan diferensial biasa orde 2 tak homogen dapat digunakan untuk memodelkan berbagai masalah nyata antara lain dalam bidang kedokteran khususnya tentang kehamilan. Penelitian ini mengkaji model mood swing ibu hamil di kota Palu pada trimester pertama berdasarkan karakternya melalui persamaan diferensial biasa orde 2 tak homogen.

\section{METODE PENELITIAN}

Jenis data yang digunakan dalam penelitian ini adalah data kuantitatif. Untuk data kadar hormon diperoleh dari dr. Didi, Sp.OG dengan kadar Estradiol dan kadar Progesteron pada kehamilan trimester pertama adalah $2-5 \mathrm{pg} / \mathrm{mL}$ dan $10-50 \mathrm{ng} / \mathrm{mL}$. Dengan prosedur penelitian sebagai berikut:।

a. Mengkaji literatur untuk meninjau persamaan diferensial biasa orde 2 tak homogen dengan sistem pegas massa. 
b. Membuat moodchart dan kuisioner tes kepribadian yang digunakan untuk memperoleh data grafik mood responden.

c. Mengaitkan model mood swing ibu hamil yang diadaptasi dari persamaan sistem pegas massa sehingga diperoleh persamaan diferensial orde 2 tak homogen.

d. Membuat simulasi.

e. Menyimpulkan hasil penelitian.

III. HASIL DAN PEMBAHASAN

\subsection{Sistem Massa Pegas}

Persamaan diferensial biasa orde 2 tak homogen yang digunakan untuk mengaitkan mood swing ibu hamil pada trimester pertama diadaptasi dari persamaan sistem pegas massa [4]. Berikut ini merupakan ilustrasi dari persamaan sistem pegas massa:

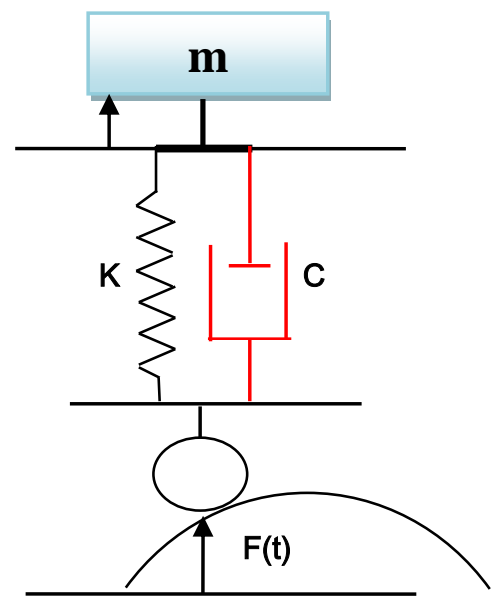

Gambar 1: Sistem Pegas Massa

Sistem gerak diilustrasikan dengan benda bermassa $m$ yang tergantung pada suatu benda, ditunjukan pada Gambar 1. Model diturunkan dari persamaan hukum Newton II dan persamaan sistem pegas massa diadaptasi menjadi model dinamika mood [2]. Berdasarkan Hukum II Newton yaitu $F=m \cdot a$ dengan $F$ adalah gaya-gaya yang bekerja pada benda. Sehingga mood akan dipengaruhi oleh tiga gaya yaitu gaya dinamik, gaya laju dan gaya eksternal. diperoleh adaptasi model sebagai berikut:

$$
\begin{aligned}
& \sum F=\frac{d^{2} R}{d t^{2}} \\
& F_{\text {dinamik }}+F_{\text {laju }}+F_{e}=\frac{d^{2} R}{d t^{2}}
\end{aligned}
$$




$$
\begin{aligned}
& -\omega^{2} R(t)-\beta \frac{d R}{d t}+F(t)=\frac{d^{2} R}{d t^{2}} \\
& F(t)=\frac{d^{2} R}{d t^{2}}+\beta \frac{d R}{d t}+\omega^{2} R(t)
\end{aligned}
$$

Model persamaan terakhir menghasilkan persamaan diferensial orde 2 tak homogen. Persamaan tersebut menggambarkan sistem gerak pada pegas dengan redaman. Model ini mengasumsikan bahwa yang mempengaruhi mood adalah hormon Estrogen dan hormon Progesteron yang dinotasikan dengan $\omega^{2}$ dan $\beta$. Berdasarkan persamaan karakteristik dari persamaan di atas terdapat tiga kasus untuk persamaan gerak teredam yaitu redaman superkritis (overdamping, $\beta^{2}>4 \omega^{2}$ ), redaman subkritis (underdamped, $\beta^{2}<4 \omega^{2}$ ), dan redaman kritis (critical damped $\beta^{2}=4 \omega^{2}$ ).

\subsection{Hasil Penelitian}

Dalam penelitian ini jumlah ibu hamil trimester pertama di Puskesmas Birobuli pada bulan April sampai Mei adalah 55 dari 361 ibu hamil. Data diperoleh dari Jamkesmas 27 ibu hamil, Askes 110 ibu hamil dan Umum 224 ibu hamil. Untuk data tingkat mood diperoleh dari mood chart yang dibagikan pada 55 ibu hamil pada trimester pertama selama 28 hari tepatnya pada periode minggu ke-6 sampai 10 . Sedangkan data karakter diperoleh dari kuisioner tes kepribadian sehingga masing-masing karakter diperoleh sanguinis 12 ibu hamil, melankolis 14 ibu hamil, koleris 13 ibu hamil dan plegmatis 16 ibu hamil.

Menurut Florence Littauer dalam bukunya Personality Plus, terdapat 4 jenis kepribadian manusia yang sering sekali dijadikan acuan untuk menganalisis kepribadian. Empat kepribadian tersebut adalah sanguinis, melankolis, koleris dan plegmatis [1]. Saat nilai $\omega^{2} \geq 4$ mood seseorang cenderung fluktuatif sedangkan $\omega^{2} \leq 4$ mood seseorang cenderung stabil. Untuk nilai $\beta$ positif moochya cenderung positif dan untuk nilai $\beta$ negatif moochya cenderung negatif.

\section{a. Karakter Koleris}

Dari seluruh sampel, tipe kepribadian yang satu ini ditandai dengan selalu optimis, kreatif, tidak emosional dalam bertindak, tidak mudah patah semangat, bebas dan mandiri. Dari hasil simulasi didapatkan redaman superkritis (overdamping), pada karakter ini nilai $\beta$ adalah positif dan $\omega^{2} \leq 4$, sehingga mood sampel tersebut memiliki mood cenderung positif dan stabil. Persamaan karakter koleris yang diperoleh sebagai berikut:

$\frac{d^{2} R}{d t^{2}}+5 \frac{d R}{d t}+0,5 R(t)=F(t)$

dengan 
$\mathrm{F}(\mathrm{t})=\sin (0,35 \pi \mathrm{t})+\mathrm{u}(\mathrm{t})$

$$
u(t)=\left\{\begin{array}{c}
0,29 \text { jika } 1 \leq t \leq 3 \\
0,3 \text { jika } 4 \leq t \leq 5 \\
0,31 \text { jika } 6 \leq t \leq 8 \\
0,25 \text { jika } 9 \leq t \leq 15 \\
0,19 \text { jika } 16 \leq t \leq 17 \\
0,28 \text { jika } 18 \leq t \leq 19 \\
0,17 \text { jika } 20 \leq t \leq 22 \\
0,01 \text { jika } 23 \leq t \leq 24 \\
0,09 \text { jika } 25 \leq t \leq 28
\end{array}\right.
$$

berikut merupakan simulasi sampel koleris dilakukan pada saat $t=1, \ldots \ldots \ldots, 28$ adalah:

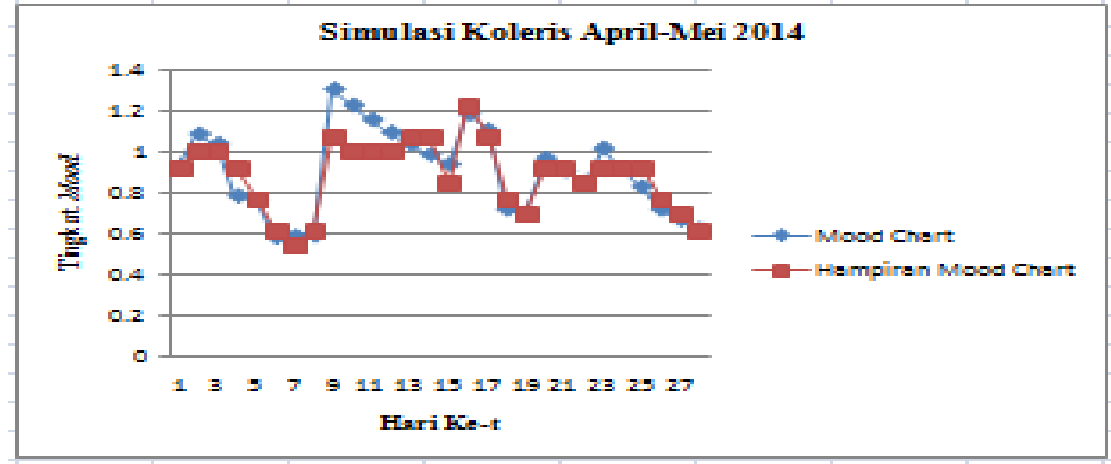

Gambar 2: Simulasi Koleris

Pada Gambar 2, tingkat mood untuk 13 ibu hamil yang diperoleh dari mood chart pada hari 1-28 memiliki suasana hati yang dominan datar, dan suasana hati dalam keadaan baik. Dengan $R(t)$ merupakan tingkat mood pada hari ke-t untuk mood chart dan $x(t)$ tingkat mood pada hari ke-t untuk hampiran mood chart. Sehingga didapatkan rataan kuadrat sisa untuk simulasi ini sebesar:

$\frac{\sum_{t=1}^{28}(R(t)-x(t))^{2}}{\sum_{1}^{28} t}=0,0071$

\section{b. Karakter Melankolis}

Dari seluruh sampel, tipe kepribadian yang satu ini biasanya ditandai dengan keperibadian perasa terhadap ibu hamil lain, tekun, mudah bersedih, cenderung jenius, berbakat dan kreatif. Dari hasil simulasi didapatkan redaman superkritis (overdamping), pada karakter ini nilai $\beta$ adalah negatif tatapi nilai $\omega^{2} \leq 4$, sehingga mood sampel tersebut memiliki mood cenderung negatif namun tetap stabil. Persamaan karakter melankolis yang diperoleh sebagai berikut:

$\frac{d^{2} R}{d t^{2}}-3,5 \frac{d R}{d t}-0,4 R(t)=F(t)$ 
dengan

$F(t)=\sin (\pi t)+u(t)$

$u(t)=\left\{\begin{array}{c}-0,7 \text { jika } 1 \leq t \leq 2 \\ 0,02 \text { jika } 3 \leq t \leq 5 \\ 0,32 \text { jika } 6 \leq t \leq 7 \\ 0,23 \text { jika } 8 \leq t \leq 10 \\ 0,14 \text { jika } 11 \leq t \leq 15 \\ 0,25 \text { jika } 16 \leq t \leq 19 \\ 0,35 \text { jika } 20 \leq t \leq 21 \\ 0,21 \text { jika } 22 \leq t \leq 28\end{array}\right.$

berikut merupakan simulasi sampel melankolis yang dilakukan pada saat $t=1, \ldots \ldots, 28$ adalah:

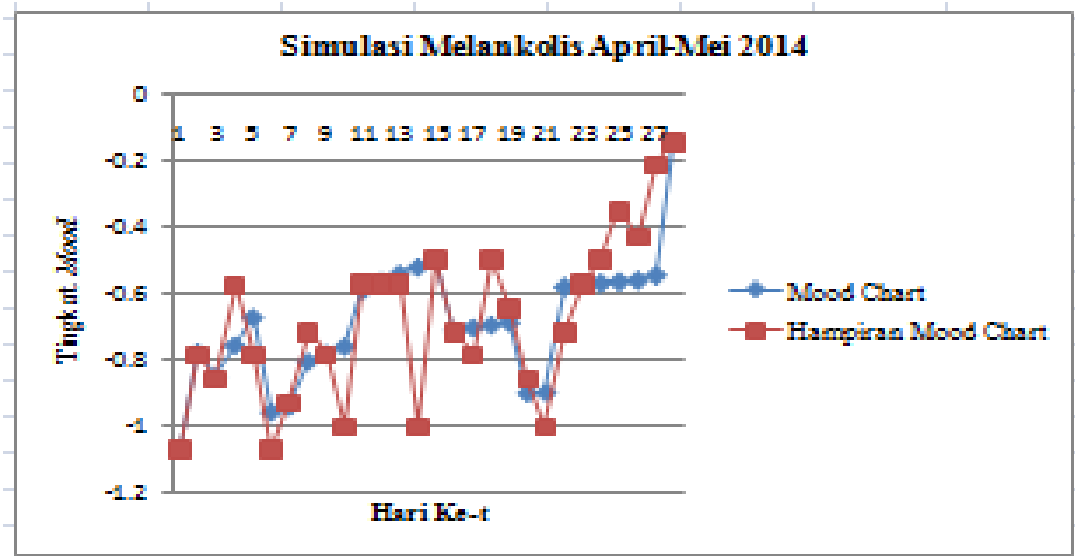

Gambar 3: Simulasi Melankolis

Pada Gambar 3, tingkat mood untuk 14 ibu hamil yang diperoleh dari mood chart pada hari 1 - 28 memiliki suasana hati yang cenderung sedih, suasana hati dalam keadaan tidak baik dan dominan datar, tenang dan suasana hati dalam keadaan baik. Dengan $R(t)$ merupakan tingkat mood pada hari ke-t untuk mood chart dan $x(t)$ tingkat mood pada hari ke-t untuk hampiran mood chart. Sehingga didapatkan rataan kuadrat sisa untuk simulasi ini sebesar: $\frac{\sum_{\mathrm{t}=1}^{28}(R(t)-x(t))^{2}}{\sum_{1}^{28} t}=0,00002$

\section{c. Karakter Plegmatis}

Dari seluruh sampel, tipe kepribadian yang satu ini ditandai dengan rendah hati, mudah bergaul, santai, diam, tenang, sabar, baik keseimbangannya, hidup konsisten, tenang tetapi cerdas, menyembunyikan emosi dan bahagia menerima kehidupan. Dari hasil simulasi didapatkan redaman superkritis (overdamping), pada karakter ini didapatkan nilai $\beta$ adalah positif dan $\omega^{2} \leq 4$, sehingga mood sampel tersebut memiliki mood cenderung positif dan stabil. Persamaan karakter plegmatis yang diperoleh sebagai berikut: 
$\frac{d^{2} R}{d^{2}}+4 \frac{d R}{d t}+0,3 R(t)=F(t)$

dengan

$\mathrm{F}(\mathrm{t})=\sin (\pi \mathrm{t})+\mathrm{u}(\mathrm{t})$

$u(t)=\left\{\begin{array}{c}0,65 \text { jika } 1 \leq t \leq 4 \\ 0,69 \text { jika } 5 \leq t \leq 11 \\ 0,72 \text { jika } 12 \leq t \leq 15 \\ 0,77 \text { jika } 16 \leq t \leq 20 \\ 0,85 \text { jika } 21 \leq t \leq 28\end{array}\right.$

berikut merupakan simulasi sampel plegmatis yang dilakukan pada saat $t=1, \ldots \ldots, 28$ adalah:

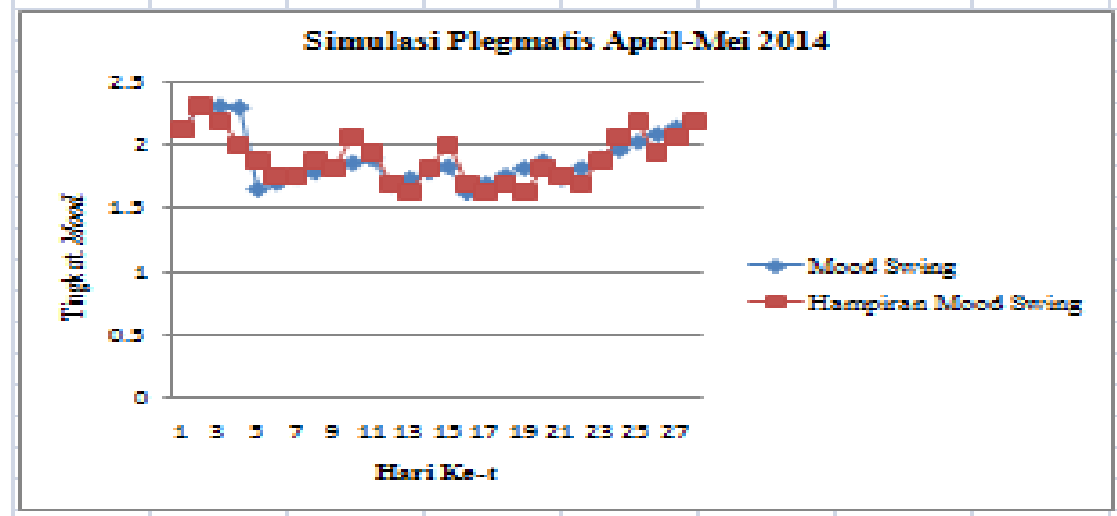

Gambar 4: Simulasi Plegmatis

Pada gambar 4, tingkat mood untuk 16 ibu hamil yang diperoleh dari mood chart pada hari 1 - 28 memiliki suasana hati yang tenang, dominan suasana hati dalam keadaan baik dan bersemangat. Dengan $R(t)$ merupakan tingkat mood pada hari ke-t untuk mood chart dan $x(t)$ tingkat mood pada hari ke-t untuk hampiran mood chart. Sehingga didapatkan rataan kuadrat sisa untuk simulasi ini sebesar:

$\frac{\sum_{\mathrm{t}=1}^{28}(\mathrm{R}(\mathrm{t})-\mathrm{x}(\mathrm{t}))^{2}}{\sum_{1}^{28} \mathrm{t}}=0,000009$

d. Karakter Sanguinis

Dari seluruh sampel, tipe kepribadian yang satu ini biasanya ditandai dengan kepribadian yang menarik, suka bicara, antusias, periang berhati tulus, dan selalu kekanakkanakan. Dari hasil simulasi didapatkan redaman superkritis (overdamping), pada karakter ini nilai $\beta$ adalah positif dan $\omega^{2} \leq 4$, sehingga mood sampel tersebut memiliki mood cenderung positif dan stabil. Persamaan karakter sanguinis yang diperoleh sebagai berikut:

$\frac{d^{2} R}{d t^{2}}+4,8 \frac{d R}{d t}+0,26 R(t)=F(t)$ 
dengan

$\mathrm{F}(\mathrm{t})=\sin (0,85 \mathrm{mt})+\mathrm{u}(\mathrm{t})$

$u(t)=\left\{\begin{array}{c}0,41 \text { jika } 1 \leq t \leq 7 \\ 0,44 \text { jika } 8 \leq t \leq 11 \\ 0,57 \text { jika } 12 \leq t \leq 14 \\ 0,45 \text { jika } 15 \leq t \leq 28\end{array}\right.$

berikut merupakan simulasi sampel sanguinis dilakukan pada saat $t=1, \ldots, 28$ adalah:

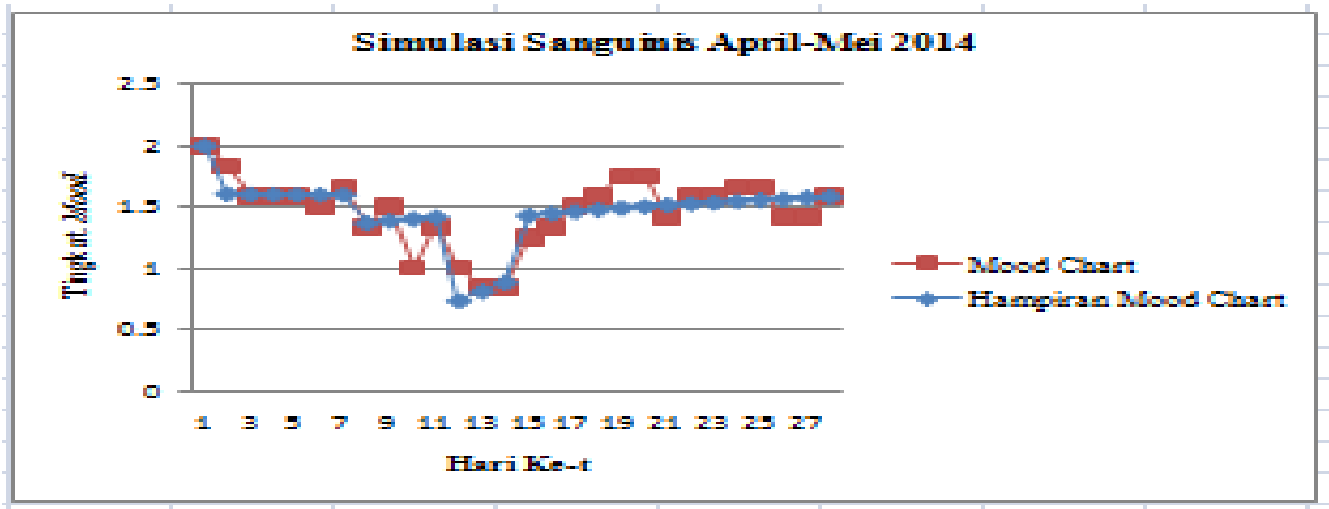

Gambar 5: Simulasi Sanguinis

Pada gambar 5, tingkat mood untuk 12 ibu hamil yang diperoleh dari mood chart pada hari 1-28 memiliki suasana hati yang dominan datar, tenang dan suasana hati dalam keadaan baik. Dengan $R(t)$ merupakan tingkat mood pada hari ke-t untuk mood chart dan $x(t)$ tingkat mood pada hari ke-t untuk hampiran mood chart. Sehingga didapatkan rataan kuadrat sisa untuk simulasi ini sebesar:

$\frac{\sum_{t=1}^{28}(R(t)-x(t))^{2}}{\sum_{1}^{28} t}=0,0027$

\section{KESIMPULAN}

Berdasarkan penelitian yang telah dilakukan, diambil kesimpulan sebagai berikut:

1. Model persamaan diferensial biasa orde 2 tak homogen dapat dikaitkan dengan mood swing ibu hamil pada kehamilan trimester pertama. Model ini diturunkan dari persamaan hukum Newton II dan persamaan sistem pegas massa sehingga diperoleh dinamika mood ibu hamil di kota Palu. Adaptasi model yang didapatkan untuk persamaan diferensial orde 2 tak homogen yang mengaitkan mood swing adalah $\frac{d^{2} R}{d t^{2}}+\beta \cdot \frac{d R}{d t}+\omega^{2} \cdot R(t)=$ $F(t)$, dengan $\beta$ adalah perubahan kadar Progesteron per hari dan $\omega^{2}$ adalah kecepatan 
perubahan kadar Estrogen per hari. Persamaan tersebut menggambarkan sistem gerak pada pegas dengan redaman.

2. Dari formulasi model dilakukan simulasi grafik mood, data sampel diambil dari para ibu hamil yang berkonsultasi di Puskesmas Birobuli pada bulan April sampai Mei tahun 2014. Dari simulasi sampel yang diambil didapatkan pada karakter koleris memiliki mood cenderung positif dan stabil dengan nilai $\beta=4$ dan $\omega^{2}=0,3$. Karakter melankolis memiliki mood cenderung negatif namun tetap stabil dengan nilai $\beta=-3,5$ dan $\omega^{2}=-0,4$. Karakter plegmatis memiliki mood cenderung positif dan stabil dengan nilai $\beta=4$ dan $\omega^{2}=$ 0,3 . Sedangkan karakter sanguinis memiliki mood cenderung positif dan stabil dengan nilai $\beta=4,8$ dan $\omega^{2}=0,26$. Untuk 4 karakter tersebut memiliki suasana hati yang dominan datar, tenang dan suasana hati dalam keadaan baik. Sehingga dapat disimpulkan bahwa trimester pertama pada ibu hamil tidak selalu mempengaruhi mood, faktor lingkungan lebih banyak mempengaruhi mood pada ibu hamil.

\section{DAFTAR PUSTAKA}

[1] Littauer dan Florence. 1996. Personality Plus. Binarupa Aksara. Jakarta.

[2] Nursyahbani, Awalia dan Nuraini, Nuning, 2009. Model Matematika Pengaruh Dinamika Perasaan Terhadap Pre Menstruation Syndrome. ITB. Bandung.

[3] Nyndia dan Zurriat, 2013. Perubahan Mood yang Drastis Saat Hamil. www.vemale.com, diakses 1 Februari 2014.

[4] Pramono, H. A.. 2012. Matematika Terapan 1. Universitas Brawijaya. Malang. 